\title{
Implementing heat transfer resistivity as a key element in a nanocrystalline diamond based single nucleotide polymorphism detection array
}

\author{
K. Bers ${ }^{\mathrm{a}, *, 1}$, B. van Grinsven ${ }^{\mathrm{a}, 1}$, T. Vandenryt ${ }^{\mathrm{a}, \mathrm{b}}$, M. Murib ${ }^{\mathrm{a}}$, W. Janssen ${ }^{\mathrm{a}, \mathrm{c}}$, B. Geerets ${ }^{\mathrm{a}}$, M. Ameloot ${ }^{\mathrm{d}}$, \\ K. Haenen ${ }^{\mathrm{a}, \mathrm{c}}$, L. Michiels ${ }^{\mathrm{d}}$, W. De Ceuninck ${ }^{\mathrm{a}, \mathrm{c}}$, P. Wagner ${ }^{\mathrm{a}, \mathrm{c}}$ \\ ${ }^{a}$ Hasselt University, Institute for Materials Research, Wetenschapspark 1, B-3590 Diepenbeek, Belgium \\ ${ }^{\mathrm{b}}$ XIOS University College, Department of Applied Engineering, Agoralaan - Building H, B-3590 Diepenbeek, Belgium \\ c IMOMEC, Wetenschapspark 1, B-3590 Diepenbeek, Belgium \\ ${ }^{\mathrm{d}}$ Hasselt University, Biomedical Research Institute, Agoralaan, B-3590 Diepenbeek, Belgium
}

\section{A R T I C L E I N F O}

\section{Article history:}

Received 29 March 2013

Received in revised form 5 June 2013

Accepted 13 June 2013

Available online 24 June 2013

\section{Keywords:}

CVD diamond

Heat transfer resistance

Mutation analysis

Array

\begin{abstract}
A B S T R A C T
In this article, we report on the label-free real-time thermal monitoring of the denaturation of specific DNA fragments and its potential to detect and quantify single nucleotide polymorphisms (SNPs). Probe DNA, consisting of a 36-mer fragment was covalently immobilized on nanocrystalline chemical vapour deposition (CVD) diamond platforms and hybridized with a 29-mer target DNA fragment (full matching and/or with a point mutation). It was observed that the change in heat transfer resistance upon denaturation is dependent on the amount of DNA hybridized to the nanocrystalline diamond (NCD) surface. Furthermore the possibility to distinguish between a full matching sequence and its singularly mutated counterpart, when bound to the same NCD surface, was investigated. NCD surfaces were selectively hybridized with both full matching and mutated DNA fragments at different ratios (3:1, 2:2 and 1:3). A clear bipartite response in heat transfer resistivity was observed upon simultaneous denaturation of these DNA fragments. Denaturation temperature could be used to identify the DNA fragment to which each partial response could be attributed. Moreover, the partial increases in heat transfer resistivity related to the hybridized amount of non-mutated or mutated DNA, respectively. These results imply that heat transfer resistivity is a technique which can be used to (i) quantify DNA fragments of interest, (ii) detect and (iii) quantify SNPs in a mixture of mutated and non-mutated DNA fragments. Moreover, it illustrates the potential of this technique to detect SNPs without the necessity to design complex microarrays.
\end{abstract}

(c) 2013 Elsevier B.V. All rights reserved.

\section{Introduction}

Diamond has proven to be an excellent platform for biomedical research due to its outstanding material properties such as chemical inertness, high thermal conductivity, and electronic properties [1]. In addition, intrinsic diamond displays a high chemical and electrochemical stability and has a wide band gap (5.5 eV) [2-4]. In recent years there has been a major development of DNA electrochemical biosensors such as field-effect sensors [5-7] and sensors monitoring electrical surface properties such as conductance, resistance [8] and

\footnotetext{
* Corresponding author. Tel.: + 32112688 93; fax: +32 11268899.

E-mail addresses: karolien.bers@uhasselt.be (K. Bers),

Bart.vanGrinsven@uhasselt.be (B. van Grinsven), Thijs.Vandenryt@xios.be (T. Vandenryt), Mohammed.Murib@uhasselt.be (M. Murib),

Wiebke.Janssen@uhasselt.be (W. Janssen),Bram.Geerets@student.uhasselt.be (B. Geerets), Marcel.Ameloot@uhasselt.be (M. Ameloot), Ken.Haenen@uhasselt.be (K. Haenen), Luc.Michiels@uhasselt.be (L. Michiels), Ward.DeCeuninck@uhasselt.be (W. De Ceuninck), Patrick.Wagner@uhasselt.be (P. Wagner).

${ }^{1}$ Both authors contributed equally.
}

capacitance [9]. In addition, diamond proved to be a good transducer for protein sensing as well [10-12]. In previous work it was established that the monitoring of changes in heat transfer resistance of double stranded DNA (dsDNA), which was single stranded covalently bound to a nanocrystalline diamond (NCD) surface, upon denaturation is an interesting approach to measure duplex stability and as such discriminate between different DNA sequence fragments [13]. The change in heat transfer resistance upon denaturation of the dsDNA to ssDNA was hypothesized to be due to the difference in geometrical configuration between dsDNA and ssDNA, which is, respectively, collapsed or erected on the surface. In the future this technique can allow for the development of a fast and low effort, label-free biosensor to detect gene sequence polymorphism based hereditary diseases such as Alzheimer's disease [14], phenylketonuria [15] and specific types of cancer [16]. Alternatively, a biosensor to distinguish between closely related target and non-target organisms, based on 16S rRNA gene sequence polymorphisms, can be developed with this technique. Such a sensor would be widely applicable to detect human pathogens in patients $[17,18]$, food industry [19] and 
drinking water production, to identify plant pathogens in agriculture [20] or to detect bacterial contaminants during food production [21]. Elaborating on previous results [13] this study focuses on the effect size of heat transfer resistance changes as a function of the attached amount of target DNA. For this purpose, hybridization was restricted to a range of specific areas of the NCD surface. To do so, a PDMS flow cell was designed to divide the NCD surface in four identical and fully isolated areas, in which hybridization could take place. The change in heat transfer resistance in response to denaturation was analysed in function of hybridization surface coverage $(25 \%, 50 \%$, $75 \%$ or $100 \%$ ). Secondly, it is investigated if one can distinguish between a full matching sequence and a point mutated sequence when bound to the same NCD surface. The same PDMS flow cell was used to selectively hybridize NCD surfaces with full matching DNA fragments and singularly mutated sequences at different ratios (3:1, 2:2 and 1:3). It was investigated whether the theoretical difference in stability between the two types of DNA fragments would also translate into a two-step response in heat transfer resistance upon denaturation. The aim of this article is to gain insight in the surface coverage to effect size ratio as an analogue to a dose response curve and to show an early stage DNA micro-array where one can identify two different sequences with different melting temperatures by means of only two thermocouples and an adjustable heat source.

\section{Experimental}

\subsection{Synthesis of nanocrystalline diamond}

$10 \times 10 \mathrm{~mm}^{2}$ doped $(10-20 \mathrm{k} \Omega \mathrm{cm})$ p-type crystalline silicon wafers (100) were seeded with a water-based colloid of ultra-dispersed detonation (nano)diamond. NCD films with thicknesses of $\sim 300 \mathrm{~nm}$ and grain sizes of $100 \mathrm{~nm}$ were grown on this silicon substrate, using microwave plasma-enhanced chemical vapour deposition (MPECVD) in ASTEX reactor equipped with a $2.45 \mathrm{GHz}$ microwave generator. This is achieved by using a standard mixture of $15 \mathrm{sccm}$ methane gas $\left(\mathrm{CH}_{4}\right)$ and $485 \mathrm{sccm}$ hydrogen gas $\left(\mathrm{H}_{2}\right)$ to deposit the NCD thin films on the silicon wafer. The growth was performed under a pressure of 45 Torr, and temperature of $750{ }^{\circ} \mathrm{C}$, the microwave power was set to $4000 \mathrm{~W}$. The growth rate was $\sim 390 \mathrm{~nm} / \mathrm{h}$.

\subsection{Sample preparation}

Probe DNA, consisting of a 36-mer single stranded DNA (ssDNA) fragment (3'-CCA AGC CCC CAT ATG TAC CCG ACG TCC CC - A AAA AAA $\mathrm{C}_{6} \mathrm{H}_{12}-\mathrm{NH}_{2}-5^{\prime}$ ) was covalently immobilized on NCD electrodes. First, the diamond surface is hydrogenated. The hydrogenation is done at $700{ }^{\circ} \mathrm{C}$ during $30 \mathrm{~s}$ at $3500 \mathrm{~W}, 12 \mathrm{kPa}$ and $1000 \mathrm{sccm}$ hydrogen gas $\left(\mathrm{H}_{2}\right)$ [22]. After hydrogenation the samples are placed inside a glovebox under nitrogen atmosphere. The hydrogenated NCD is then covered with a thin film of unsaturated fatty acid (10-undecenoic acid) and exposed to UV radiation $\left(254 \mathrm{~nm}, 265 \mathrm{~mW} / \mathrm{cm}^{2}\right)$ for $20 \mathrm{~h}$ under nitrogen atmosphere. The double bonds of the unsaturated fatty acid chains will break and a covalent bond with the hydrogen-terminated diamond is established. This process is mediated by photoemission from the surface as proposed for the photochemical grafting of alkenes to silicon surfaces $[3,4]$. The fatty acid layer is about $2 \mathrm{~nm}$ thick [23]. The unbound fatty acid chains are washed off using acetic acid and milliQ water at $120^{\circ} \mathrm{C}$. In this way a carboxyl $(\mathrm{COOH})$ terminated NCD surface is obtained. Zero-length 1-ethyl-3-[3-dimethylaminopropyl]-carbodiimide (EDC) is used for the covalent coupling of the $5^{\prime}$ side of an amino-modified 36-mer ssDNA fragment to the carboxyl-terminated surface in 2-[N-morpholino]-ethannesulphonic acid (MES) buffer at $4{ }^{\circ} \mathrm{C}$. These conditions were previously reported to result in a probe areal density of $8 \times 10^{12} / \mathrm{cm}^{2}$, as evaluated by X-ray photoemission spectroscopy [13].

\subsection{PDMS flow cell}

A mold is fabricated in Teflon (PTFE) to serve as the master template, through numerical control milling. Four identical triangles, which occupy an area of $10 \mathrm{~mm}^{2}$ each, with a height of $1 \mathrm{~mm}$ are cut from a PTFE block, as can be seen in Fig. 1. The master mold is then encapsulated in uncured polydimethylsiloxane (PDMS) polymer (Sylgard 184, Dow Corning), which is mixed in a 10:1 ratio with the curing agent. The mixture is degassed for $30 \mathrm{~min}$ at an absolute pressure of $50 \mathrm{kPa}$, to remove trapped gas bubbles. Curing of the PDMS in an oven at $120{ }^{\circ} \mathrm{C}$ takes approximately $20 \mathrm{~min}$. The cured daughter-mold can be gently peeled from the master template and cut to the required dimensions with a lancet. A biopsy punch (Miltex) with a $1 \mathrm{~mm}$ inner diameter is used to core both an inlet and outlet as connection ports for each triangular cavity. PTFE tubing (1.2 mm outer diameter) is press-fitted in the connection ports [24], to form a reliable connection without additional bonding or molding. Finally, the PDMS mold is pressed onto the diamond covered silicon substrate. As such it provides four completely separated identical areas for hybridization on the NCD sample.

\subsection{Selective hybridization}

In a following step, $6 \mu$ Alexa-488-modified ssDNA ( $100 \mathrm{pmol} / \mu \mathrm{l})$ is mixed with $14 \mu \mathrm{l} 1 \times$ PCR buffer and per $\mathrm{mm}^{2} 4 \mu \mathrm{l}$ of this mixture was selectively added to specific areas of the ssDNA-modified NCD sample by means of the PDMS flow cell. As such, about $10^{5}$ times more DNA is provided for hybridization than probe DNA is available on the NCD surface. The sample is then incubated at $35{ }^{\circ} \mathrm{C}$ for $2 \mathrm{~h}$ for hybridization to take place. Non-specifically bound DNA is removed using a double washing step. In a first step, the sample is washed with $2 \times$ saline sodium citrate (SSC) $+0.5 \%$ sodium dodecyl sulphate (SDS) for $30 \mathrm{~min}$. Secondly, the sample is washed twice with $0.2 \times \mathrm{SSC}$ at $30{ }^{\circ} \mathrm{C}$ for $5 \mathrm{~min}$. Finally, the sample is rinsed with phosphate buffered saline (PBS) of pH 7.2 and stored in PBS at $4{ }^{\circ} \mathrm{C}[2]$. The use of low salt concentrations in comparison to the hybridization buffer and by washing at temperatures lower than hybridization temperature, premature denaturation is avoided. Both full match ssDNA fragments (5'-GGT TCG GGG GTA TAC ATG GGC TGC AGG GG-3') and ssDNA fragments with a point mutation at position 20 (5'-GGT TCG GGG CTA TAC ATG GGC TGC AGG GG-3') were used for hybridization. Because of the abundant amount of DNA provided for hybridization, all probes available on the NCD surface can be assumed hybridized.

\subsection{Fluorescence imaging}

Fluorescence images were taken on a Zeiss LSM 510 META Axiovert $200 \mathrm{M}$ laser scanning confocal fluorescence microscope. To excite the FAM-488 fluorescence dye, a $488 \mathrm{~nm}$ argon-ion laser was used with a maximum intensity at the sample surface of $30 \mu \mathrm{W}$ to avoid bleaching during the image acquisition. The peak emission has a longer wavelength of $518 \mathrm{~nm}$ due to vibrational relaxation of the FAM molecule after photon absorption. All images were collected with a $10 \times 0.3$ Plan Neofluar air objective with a working distance of $5.6 \mathrm{~mm}$. The pinhole size was $150 \mu \mathrm{m}$ and the laser intensity was set at $10 \%$. The detector gain, being a measure for the photomultiplier

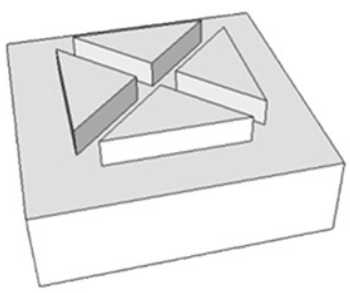

Fig. 1. CAD drawing of the flow cell master mold. 
voltage in arbitrary units, was set to 950. The fluorescent intensity was analysed using ImageJ software.

\subsection{Experimental setup}

The general principle of the heat-transfer method is shown in Fig. 2. The central element of the platform consists of an adjustable heat source attached to a copper block that transfers a thermal current trough the NCD chip $\left(1 \times 1 \mathrm{~cm}^{2}\right)$, selectively hybridized with DNA. During measurements, the temperature above the NCD chip, $T_{1}$, is stringently stabilized with a PID controller and the temperature $T_{2}$, in the liquid compartment underneath the NCD, is monitored. From the temperature difference $T_{1}-T_{2}$ and the required heating power $P$ to keep the copper block at the selected temperature, one can derive the heat transfer resistance from $R_{\text {th }}=\left(T_{1}-T_{2}\right) / P[25,26]$. The contact area between the chip and the liquid compartment was $28 \mathrm{~mm}^{2}$.

\subsection{Surface coverage to effect size ratio}

Diamond-coated silicon electrodes used were denoted as \#D1, \#D2 and \#D3. In this experiment only fully complementary DNA fragments were used for hybridization. The PDMS flow cell was used to limit hybridization to distinct parts of the NCD surface by performing hybridization in one, two, three or four out of four hybridization chambers. Hybridization was performed on $25 \%$ of the occupational zone $\left(10 \mathrm{~mm}^{2}\right)$ for sample \#D1, 50\% (20 mm²) for sample \#D2, 75\% (30 $\left.\mathrm{mm}^{2}\right)$ for sample \#D3 and sample \#D1 was reused to hybridize 100\% of the occupational zone $\left(40 \mathrm{~mm}^{2}\right)$. During the measurement, $\mathrm{T}_{1}$ was increased with a heating rate of $1{ }^{\circ} \mathrm{C} / \mathrm{min}$ from $35{ }^{\circ} \mathrm{C}$ to $90{ }^{\circ} \mathrm{C}$ and cooled back to $35^{\circ} \mathrm{C}$ at the same rate by reducing the heating power. This was performed for two consecutive heating/cooling runs.

\subsection{SNP detection array}

The second series of experiments refers to a combination of fully complementary duplexes and mismatched duplexes hybridized on the same NCD coated electrode. Goal of this experiment was to evaluate if discrimination between full matching DNA sequences and mutated sequences is possible based on heat transfer resistivity changes upon denaturation, when hybridized to the same sample. The PDMS flow cell provided four separated hybridization areas and as such could be used to hybridize full matching sequences (FM) on the one hand and singularly mutated sequences (1MM) on the other hand simultaneously on separated distinct parts of the NCD surface. This to provide unbiased hybridization of both types of DNA fragments. Sample \#D1 was hybridized with full matching sequences and singularly mutated sequences at a FM:1MM ratio of 3:1, hybridized sample \#D2 at a FM:1MM ratio of 2:2 and finally hybridized sample \#D3 at a FM:1MM ratio of 1:3, in the PDMS flow cell. After the samples were mounted into the setup, $\mathrm{T}_{1}$ was increased with a heating rate of $1{ }^{\circ} \mathrm{C} / \mathrm{min}$ from $35{ }^{\circ} \mathrm{C}$ to $90{ }^{\circ} \mathrm{C}$ and cooled back to $35{ }^{\circ} \mathrm{C}$ at the same rate by reducing the heating power.

\section{Experimental results}

\subsection{Surface coverage to effect size ratio}

The goal of this experiment was to analyse the effect of variations in the amount of DNA hybridized to the functionalized diamond surface on the size of heat transfer resistance change upon denaturation. Hybridizing restricted areas with $100 \%$ hybridization density was preferred upon hybridizing complete NCD samples (100\% hybridization surface coverage) with different concentrations of the target DNA provided in the hybridization solution. This because changing the amount of DNA provided for hybridization will lead to different hybridization densities of the NCD sample, however without being able to derive the resulting hybridization density directly from the variation in concentration in the hybridization solution. Therefore no information on the actual amount of DNA hybridized on the NCD sample would be easily available with this approach. In order to hybridize restricted areas with $100 \%$ hybridization density, hybridization was restricted to a range of specific areas of the NCD surface. This was established by performing hybridization with an excess of target DNA in one, two, three or all four of the separated hybridization areas created by the PDMS flow cell described above. As such NCD samples with 25\% $\left(10 \mathrm{~mm}^{2}\right), 50 \%\left(20 \mathrm{~mm}^{2}\right), 75 \%$ $\left(30 \mathrm{~mm}^{2}\right)$ or $100 \%\left(40 \mathrm{~mm}^{2}\right)$ hybridization surface coverage and maximum hybridization density within these restricted areas could be created. Fig. 3 shows fluorescent images of samples \#D1, \#D2, \#D3 when (a) $25 \%$, (b), $50 \%$, (c) $75 \%$ and (d) $100 \%$ of the occupational zone is hybridized. After the samples were mounted into the setup, $\mathrm{T}_{1}$ was increased with a heating rate of $1{ }^{\circ} \mathrm{C} / \mathrm{min}$ from $35^{\circ} \mathrm{C}$ to $90{ }^{\circ} \mathrm{C}$. Fig. 4 shows heat transfer resistance $\mathrm{R}_{\mathrm{th}}$ as a function of temperature for electrode \#D1, \#D2, \#D3 (data have not been filtered), when partially or fully hybridized. It can be seen that when $100 \%$ of the occupational zone is hybridized the intial $R_{\text {th }}$ value of double stranded DNA (black line) lies around $7{ }^{\circ} \mathrm{C} / \mathrm{W} \pm 0.08{ }^{\circ} \mathrm{C} / \mathrm{W}$ and switches to $8.5{ }^{\circ} \mathrm{C} / \mathrm{W} \pm$ $0.07{ }^{\circ} \mathrm{C} / \mathrm{W}$ upon denaturation with an inflection point in $\mathrm{R}_{\text {th }}$ at a temperature of $61.0{ }^{\circ} \mathrm{C} \pm 0.1{ }^{\circ} \mathrm{C}$. When hybridizing $75 \%$ of the

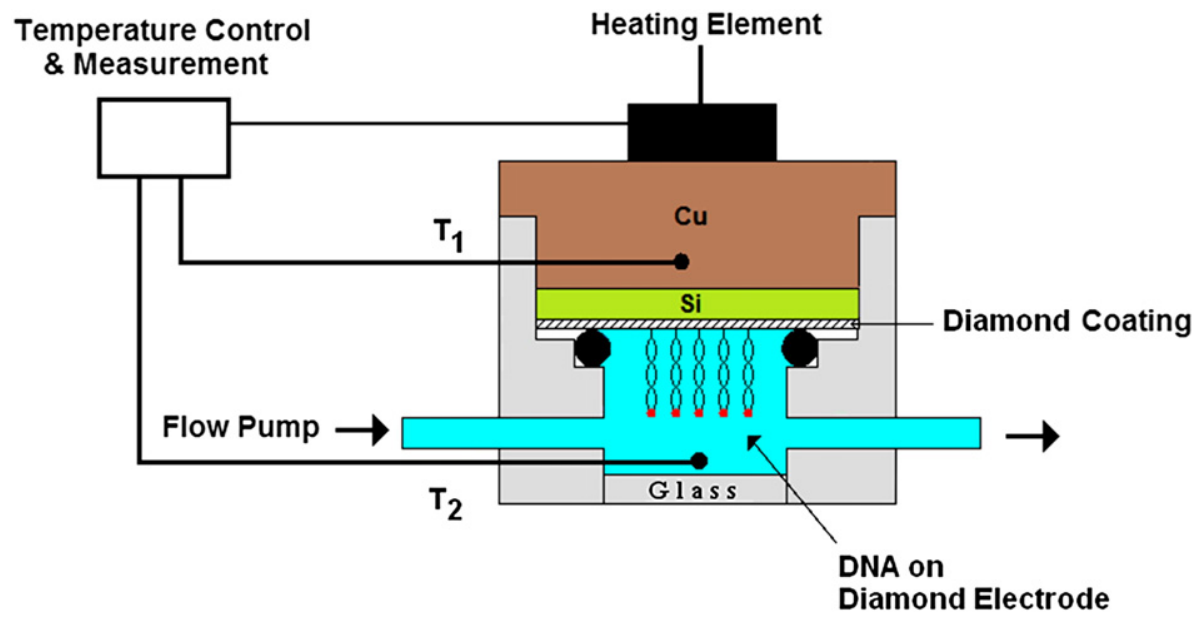

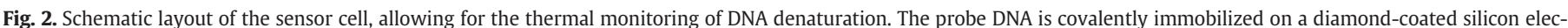

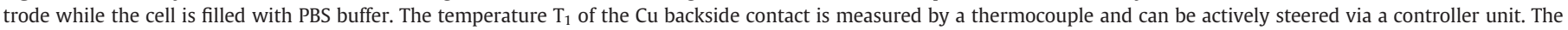

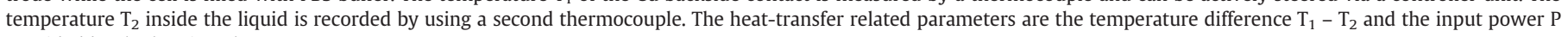
provided by the heating element. 
occupational zone (red line) the initial $\mathrm{R}_{\text {th }}$ value starts around $7.5^{\circ} \mathrm{C} /$ $\mathrm{W} \pm 0.11^{\circ} \mathrm{C} / \mathrm{W}$ and also switches to $8.5^{\circ} \mathrm{C} / \mathrm{W} \pm 0.08{ }^{\circ} \mathrm{C} / \mathrm{W}$ upon denaturation with an inflection point in $\mathrm{R}_{\mathrm{th}}$ at an identical temperature of $61.0{ }^{\circ} \mathrm{C} \pm 0.1{ }^{\circ} \mathrm{C}$. Covering $50 \%$ of the occupational state (blue line) leads to an initial $\mathrm{R}_{\text {th }}$ value of $8{ }^{\circ} \mathrm{C} / \mathrm{W} \pm 0.10^{\circ} \mathrm{C} / \mathrm{W}$ which increases to $8.7^{\circ} \mathrm{C} / \mathrm{W} \pm 0.08{ }^{\circ} \mathrm{C} / \mathrm{W}$ upon denaturation and when using only $25 \%$ of the occupational zone (grey line) one can find an initial $R_{\text {th }}$ value of $8.5{ }^{\circ} \mathrm{C} / \mathrm{W} \pm 0.07{ }^{\circ} \mathrm{C} / \mathrm{W}$ which increases to $8.9{ }^{\circ} \mathrm{C} / \mathrm{W} \pm 0.08{ }^{\circ} \mathrm{C} / \mathrm{W}$ upon denaturation.

\subsection{SNP detection array}

Fig. 5 shows confocal images of the second series of experiments. First we selectively hybridized sample \#D1 with full matching sequences and mutated sequences at a FM:1MM ratio of 3:1 as depicted in fig. 5a, then sample \#D2 was hybridized at a FM:1MM ratio of 2:2 as shown in Fig. 5b and finally Fig. 5c shows sample \#D3, hybridized at a FM:1MM ratio of 1:3. After the samples were mounted into the setup, $\mathrm{T}_{1}$ was increased with a heating rate of $1{ }^{\circ} \mathrm{C} / \mathrm{min}$ from $35{ }^{\circ} \mathrm{C}$ to $90{ }^{\circ} \mathrm{C}$ and cooled back to $35{ }^{\circ} \mathrm{C}$ at the same rate by reducing the heating power, this was done for two consecutive runs. Fig. 6 shows the correlating heat transfer resistance $\mathrm{R}_{\mathrm{th}}$ as a function of temperature. It can be seen that when hybridizing a NCD sample with full matching sequences and mutated sequences at a ratio of $3: 1$, the intial $R_{\text {th }}$ value starts around $6.9{ }^{\circ} \mathrm{C} / \mathrm{W}$, then increases to $7.5^{\circ} \mathrm{C} / \mathrm{W} \pm 0.08{ }^{\circ} \mathrm{C} / \mathrm{W}$ with an inflection point in $\mathrm{R}_{\mathrm{th}}$ at a temperature of $55.0{ }^{\circ} \mathrm{C} \pm 0.1{ }^{\circ} \mathrm{C}$ (denaturing of the mutated sequences), stabilizes and finally shows a second increase to $8.6{ }^{\circ} \mathrm{C} / \mathrm{W} \pm 0.12^{\circ} \mathrm{C} / \mathrm{W}$ (denaturing of the full matching sequences) with an inflection point in $\mathrm{R}_{\text {th }}$ at a temperature

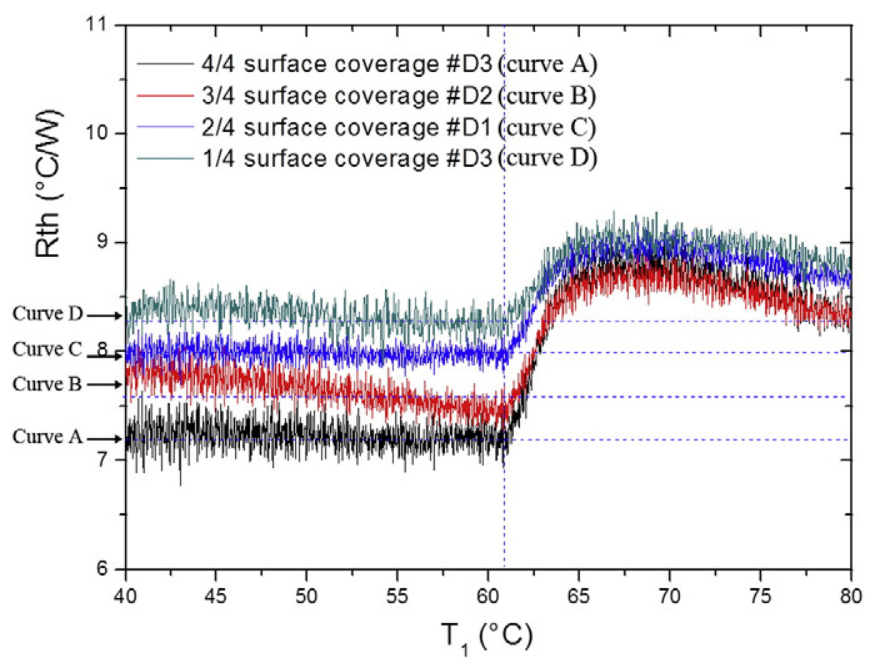

Fig. 4. Heat transfer resistance $R_{\text {th }}$ as a function of temperature when $100 \%$ ( $40 \mathrm{~mm}^{2}$ ), $75 \%\left(30 \mathrm{~mm}^{2}\right), 50 \%\left(20 \mathrm{~mm}^{2}\right)$ and $25 \%\left(10 \mathrm{~mm}^{2}\right)$ of the occupational zone of a NCD sample is hybridized.

of $61.0{ }^{\circ} \mathrm{C} \pm 0.1{ }^{\circ} \mathrm{C}$ (Fig. 6a). When hybridizing at a ratio of 2:2, a similar process is observed. The intial $\mathrm{R}_{\text {th }}$ value starts around $7.0^{\circ} \mathrm{C} / \mathrm{W}$, but then increases to $7.8{ }^{\circ} \mathrm{C} / \mathrm{W}$ with an inflection point in $\mathrm{R}_{\text {th }}$ at a temperature of $55.0^{\circ} \mathrm{C} \pm 0.1{ }^{\circ} \mathrm{C}$, stabilizes and finally shows a second increase in to $8.6{ }^{\circ} \mathrm{C} / \mathrm{W} \pm 0.13^{\circ} \mathrm{C} / \mathrm{W}$ with an inflection point in $\mathrm{R}_{\text {th }}$
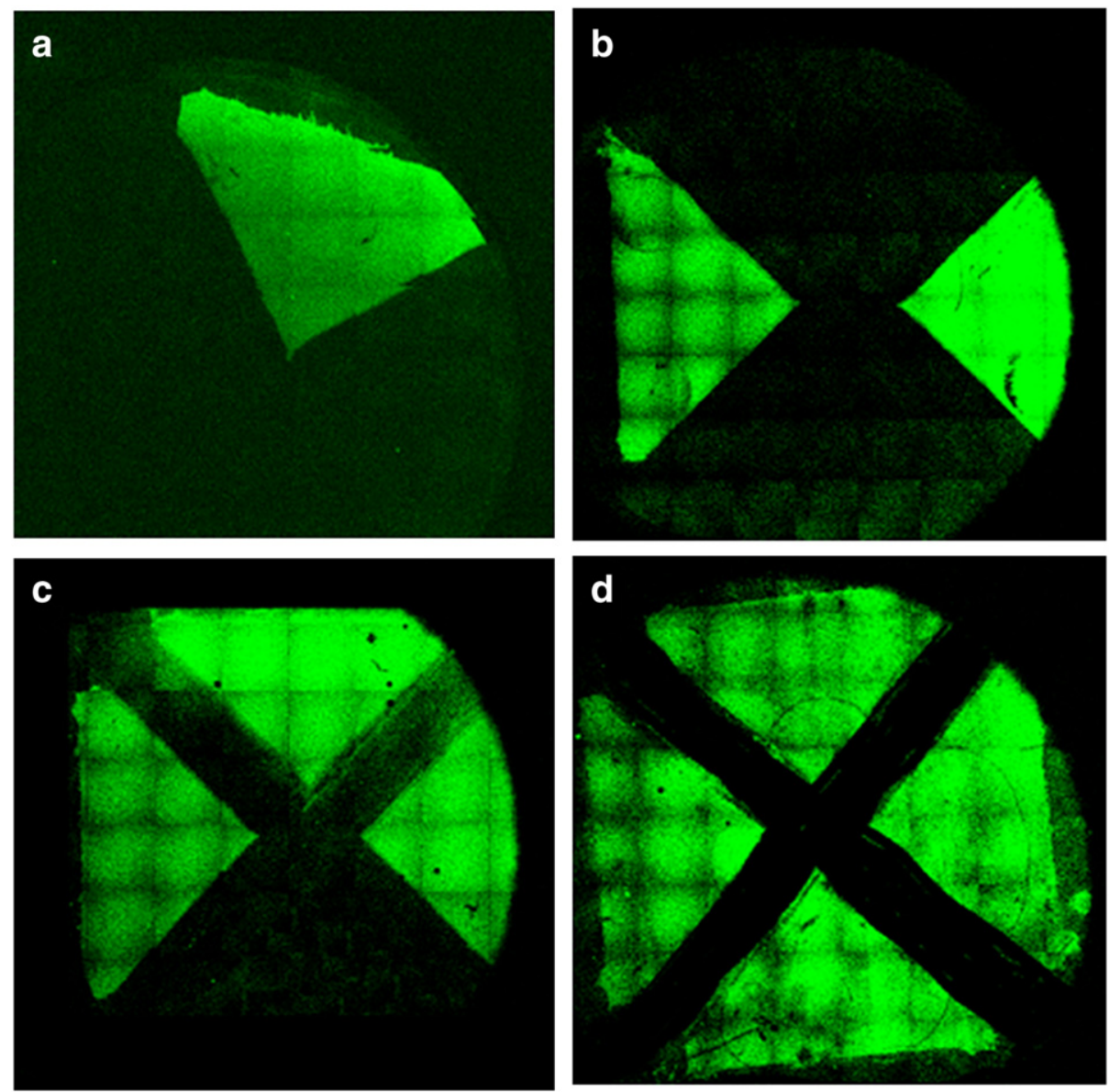

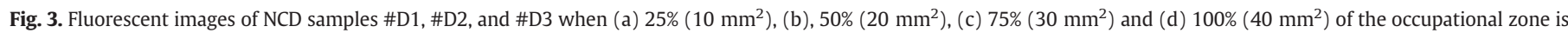
hybridized. 

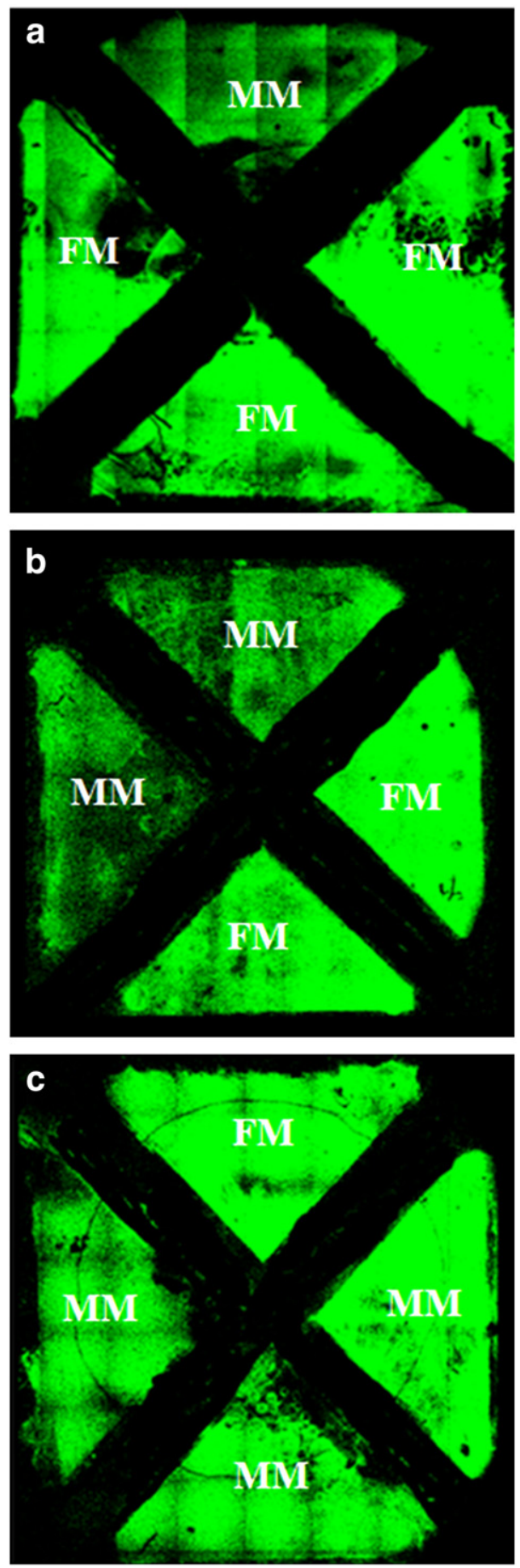

Fig. 5. Fluorescent images of NCD samples \#D1, \#D2, and \#D3 when the sample is selectively hybridized with a combination of full matching sequences and mutated sequences at a ratio of (FM:1MM) (a) 3:1, (b) 2:2 and (c) $1: 3$

at a temperature of $61.0{ }^{\circ} \mathrm{C} \pm 0.1{ }^{\circ} \mathrm{C}$ (Fig. 6b). After hybridisation at a ratio of $1: 3$, identical $R_{\text {th }}$ inflection point temperatures are found, but now a first increase in $\mathrm{R}_{\mathrm{th}}$ is observed from $7.5{ }^{\circ} \mathrm{C} / \mathrm{W} \pm 0.09{ }^{\circ} \mathrm{C} / \mathrm{W}$ to $8.5^{\circ} \mathrm{C} / \mathrm{W} \pm 0.10^{\circ} \mathrm{C} / \mathrm{W}$ and a second increase is found from $8.5^{\circ} \mathrm{C} /$ $\mathrm{W} \pm 0.09{ }^{\circ} \mathrm{C} / \mathrm{W}$ to $9.0{ }^{\circ} \mathrm{C} / \mathrm{W} \pm 0.11{ }^{\circ} \mathrm{C} / \mathrm{W}$ (Fig. 6c).

\section{Discussion}

The results show that the heat transfer resistance of NCD samples increases when less DNA is hybridized to the surface. This effect can
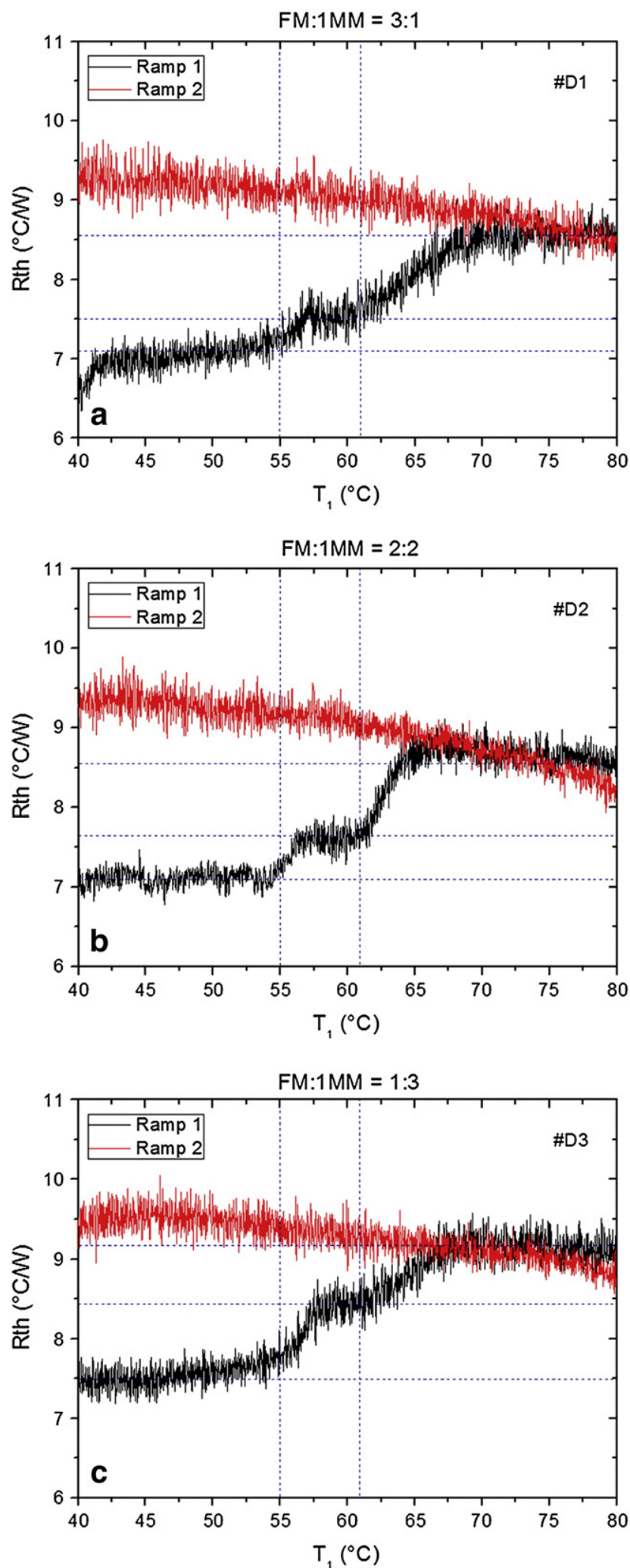

Fig. 6. Heat transfer resistance $R_{\text {th }}$ as a function of temperature, when hybridizing a NCD sample with full matching sequences (FM) and mutated sequences (1MM) at a FM:1MM ratio of 3:1 (a), 2:2 (b) and 1:3 (c).The temperature for which denaturation is initiated is marked in the graphs with a dotted line for both the mutated sequence $\left(55^{\circ} \mathrm{C}\right)$ and the fully matching sequence $\left(61^{\circ} \mathrm{C}\right)$.

be explained by the increased proportion of non-hybridized ssDNA on the surface, which coincides with a lower hybridization surface coverage. ssDNA probes were previously reported to exhibit a higher 
heat transfer resistance than hybridized dsDNA fragments [13]. This difference was hypothesized to be due to the difference in geometrical configuration between the non-hybridized and hybridized DNA fragments, which are, respectively, collapsed or erected on the surface. As a consequence, since the increase in heat transfer resistance upon denaturation is due to the conversion of dsDNA to ssDNA, also a lower change in $R_{\text {th }}$ is identified upon denaturation of samples with a low hybridization surface coverage. As is illustrated in Fig. 7, a heat transfer resistance effect size $\left(\Delta R_{\text {th }}(\%)\right.$, calculated as $\% \Delta R_{\text {th }}=$ $\left(\left(<\mathrm{R}_{\operatorname{th}\left(70-80^{\circ} \mathrm{C}\right)}>-<\mathrm{R}_{\operatorname{th}\left(40-60^{\circ} \mathrm{C}\right)}>\right) /<\mathrm{R}_{\operatorname{th}\left(40-60^{\circ} \mathrm{C}\right)}>\right) \times 100$, with $<\mathrm{R}_{\mathrm{th}}\left(40{ }^{\circ} \mathrm{C}-60{ }^{\circ} \mathrm{C}\right)>$ the average heat transfer resistance before denaturation is initiated and $<\mathrm{R}_{\operatorname{th}}\left(70{ }^{\circ} \mathrm{C}-80{ }^{\circ} \mathrm{C}\right)>$ the average heat transfer resistance after denaturation has occurred), of $7.21 \pm 1.45 \%, 10.72 \pm$ $0.97 \%, 13.67 \pm 1.84 \%$ and $18.94 \pm 1.71 \%$ was brought about upon denaturation for $25 \%\left(10 \mathrm{~mm}^{2}\right), 50 \%\left(20 \mathrm{~mm}^{2}\right), 75 \%\left(30 \mathrm{~mm}^{2}\right)$ or $100 \%\left(40 \mathrm{~mm}^{2}\right)$ of hybridization surface coverage, respectively. A positive linear relationship exists between the heat transfer resistance effect size upon denaturation and the total amount of hybridized DNA ('DNA hybr' $_{\text {' }}$ expressed as the hybridization surface coverage in $\mathrm{mm}^{2}$ ) $\left(\Delta \mathrm{R}_{\mathrm{th}}=3.15+0.38 \mathrm{DNA}_{\text {hybr }} ; \mathrm{R}^{2}=0.98\right)$, as is illustrated in Fig. 7 . This relationship allows for quantification of a DNA fragment of interest, based on its change in $R_{\text {th }}$ upon denaturation. The identified relationship indicates a minimal increase in heat transfer resistance upon temperature ramping, even when no DNA is hybridized to the NCD sample surface. This is in contrast to previously published results showing a nearly constant heat transfer resistance $\left(\Delta \mathrm{R}_{\mathrm{th}}= \pm 0\right)$ for $0 \%$ hybridization surface coverage [13]. Since the change in $R_{\text {th }}$ upon temperature ramping is caused by the denaturation of dsDNA to ssDNA at elevated temperatures, the absence of dsDNA (as is the case for $0 \%$ hybridization surface coverage) would indeed result in a constant heat transfer resistance during temperature ramping. Probably, the heat transfer resistivity technique requires a minimal amount of hybridization surface coverage before changes in heat transfer resistance upon denaturation are detected. The detection limitations of the heat transfer resistivity technique might be reduced through optimization of the signal-tonoise ratio in the future. The theoretical take-off $\Delta \mathrm{R}_{\mathrm{th}}$ value implied by Fig. 7, might be caused by these suspected detection limitations of the heat transfer resistivity technique. Heat transfer resistance measurements were previously reported to allow for discrimination between SNPs based on differences in denaturation temperature, when both gene polymorphisms were analysed separately [13]. However, up until now, no evidence was presented for the discrimination between two SNPs when both DNA fragments are hybridized to the same NCD sample surface. The results presented in the current study illustrate

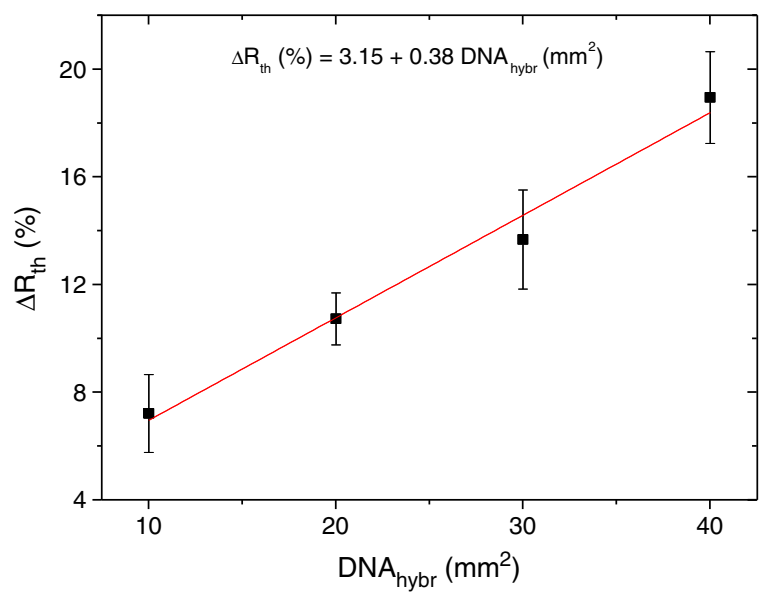

Fig. 7. Correlation between heat transfer resistance effect size upon denaturation $\left(\Delta \mathrm{R}_{\mathrm{th}}\right)$ and hybridization surface coverage (DNA $\left.\mathrm{Dhbr}_{\text {hr }}\right)$. the possibility to distinguish between a gene fragment and its SNP within the same heat transfer resistance measurement, provided a difference in denaturation temperature exists between both $\left(6{ }^{\circ} \mathrm{C}\right.$ in the current study). The heat transfer resistance change effect size upon denaturation caused by the full match DNA fragment on the one hand and the mutated DNA fragment on the other hand shows a similar increase with increased hybridization surface coverage as was observed for the singular detection of the full match gene fragment. This is depicted in Fig. 8 and illustrates the potential to determine the fraction of mutated DNA fragments in a sample of interest. The observed relationship between the hybridized amount of DNA and the heat transfer resistance effect size upon denaturation can be used to evaluate the presence of an aberrant oligonucleotide sequence, even when no sufficient difference in denaturation temperature between a DNA fragment and its nucleotide polymorphism exists. This by comparing the heat transfer resistance effect size upon denaturation after hybridization in low stringent conditions, as performed in the current study, and after hybridization in high stringent conditions. High stringent hybridization can be realized by increasing the washing temperature [27] and/or by adding formamide to the washing solution [28]. High stringent conditions should only allow for hybridization of fully matching oligonucleotide sequences, while in low stringent conditions both the fully matching sequences and the sequence polymorphisms will remain hybridized. This will result in a higher heat transfer resistance effect size upon denaturation for low stringently hybridized NCD samples as compared to high stringently hybridized NCD-samples, when a sequence polymorphism of the gene of interest is present. Although these results show that differentiation between gene sequence polymorphisms hybridized to the same NCD sample is possible with the heat transfer resistivity technique, successful analysis of mixtures of sequence polymorphisms also requires simultaneous hybridization of a mixture of different sequence polymorphisms on the same NCD sample. However, based on the theoretical higher stability of the hybridization product of the probe with the fully matching sequence as compared to the hybridization product of the probe with the nucleotide polymorphism [29], the fully matching sequence might be preferentially hybridized when in competition with mutated DNA fragments. This would interfere with the detection of low copy number SNPs. Therefore, in a next study, the heat transfer effect size upon denaturation of NCD samples hybridized with oligonucleotide solutions containing both the full matching oligonucleotide and its SNP in known ratios should be evaluated and compared with correlations between hybridization surface coverage and heat transfer effect size observed in the current study.

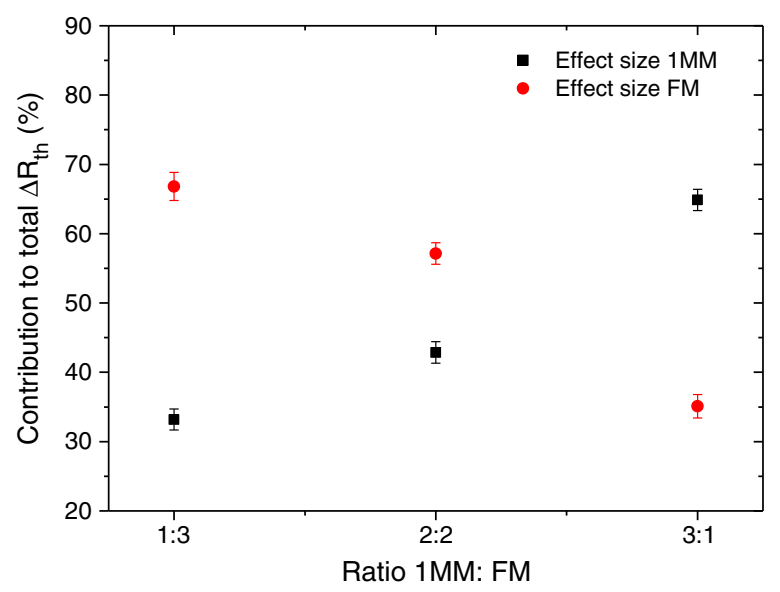

Fig. 8. Percentile contributions to the total heat transfer resistance effect size upon denaturation of the mutated sequence fragments (1MM) on the one hand and the fully complementary sequence fragments (FM) on the other hand, observed for heat transfer resistance analysis for different ratios of FM and 1MM DNA hybridized to the same NCD sample $(1: 3,2: 2,3: 1)$. 


\section{Conclusions}

This study showed the possibility to use the recently developed heat transfer resistivity procedure to determine the gene copy number of a specific gene of interest for the first time. Furthermore, it was proven that the heat transfer resistivity procedure allows for differentiation between DNA fragments representing different sequence polymorphisms of the same gene when analysed simultaneously. This illustrates the potential of this technique as a user-friendly alternative for currently widely used micro-arrays. Moreover, the procedure allows to estimate the mutated fraction of the gene of interest through simultaneous heat transfer resistance analysis of both sequence polymorphisms. Therefore, these results present the heat transfer resistivity procedure as a technique with great potential for implementation in diagnostic procedures in any field of research ranging from clinical diagnostics, environmental microbiology and microbial ecology to detect mutations or polymorphisms.

\section{Prime novelty statement}

We would like to state that the prime novelty of this work can be found in the fact that the results provided in this manuscript imply that heat transfer resistivity in combination with nanocrystalline diamond surfaces can be used to quantify DNA fragments of interest and to detect and quantify single nucleotide polymorphisms in a mixture of mutated and non-mutated DNA fragments.

\section{Acknowledgements}

Financial support by the Life-Science Initiative of the Province of Limburg, the Research Foundation Flanders FWO (Project G.0829.09 and project G.0B62.13 N) and the EU FP7 through Marie Curie ITN "MATCON" (PITN-GA-2009-238201) is greatly appreciated.

\section{References}

[1] S. Wenmackers, V. Vermeeren, M. vande Ven, M. Ameloot, N. Bijnens, K. Haenen, L. Michiels, P. Wagner, Diamond-based DNA sensors: surface functionalization and read-out strategies, Phys. Status Solidi A 206 (2009) 391-408.

[2] V. Vermeeren, S. Wenmackers, M. Daenen, K. Haenen, O.A. Williams, M. Ameloot, M. vandeVen, P. Wagner, L. Michiels, Topographical and functional characterization of the ssDNA probe layer generated through ADC-mediated covalent attachment to nanocrystalline diamond using fluorescence microscopy, Langmuir 24 (2008) 9125-9134.

[3] P. Christiaens, V. Vermeeren, S. Wenmackers, M. Daenen, K. Haenen, M. Nesládek M. vandeVen, M. Ameloot, L. Michiels, P. Wagner, DNA attachment to nanocrystalline diamond films, Biosens. Bioelectron. 22 (2006) 170-177.

[4] W. Yang, J.E. Butler, W. Cai, J. Carlisle, D. Gruen, T. Knickerbocker, J.N. Russell Jr., L.M. Smith, R.J. Hamers, DNA-modified nanocrystalline diamond thin-films as stable biologically active substrates, Nat. Mater. 1 (2002) 253-257.

[5] M. Krátká, A. Kromka, E. Ukraintsev, M. Ledinský, A. Brož, M. Kalbacova, B. Rezek Function of thin film nanocrystalline diamond-protein SGFET independent of grain size, Sens. Actuators B Chem. 166-167 (2012) 239-245.

[6] S. Ingebrandt, Y. Hana, F. Nakamura, A. Poghossian, M.J. Schöning, A. Offenhäusser, Label-free detection of single nucleotide polymorphisms utilizing the differentia transfer function of field-effect transistors, Biosens. Bioelectron. 22 (2007) 2834-2840.

[7] A. Poghossian, M.H. Abouzar, F. Amberger, D. Mayer, Y. Han, S. Ingebrandt, A Offenhäusser, M.J. Schöning, Field-effect sensors with charged macromolecules: Characterisation by capacitance-voltage, constant-capacitance, impedance spectroscopy and atomic-force microscopy methods, Biosens. Bioelectron. 22 (2007) 2100-2107.

[8] M.Yu. Vagin, A.A. Karyakin, T. Hianik, Surfactant bilayers for the direct electrochemical detection of affinity interactions, Bioelectrochemistry 56 (2002) 91-93.
[9] A. Poghossian, M.H. Abouzar, M. Sakkari, T. Kassab, Y. Han, S. Ingebrandt, A. Offenhäusser, M.J. Schöning, Field-effect sensors for monitoring the layer-by-layer adsorption of charged macromolecules, Sens. Actuators B Chem. 118 (2006) 163-170.

[10] L. Grieten, S.D. Janssens, A. Ethirajan, N. Vanden Bon, M. Ameloot, L. Michiels, K. Haenen, P. Wagner, Real-time study of protein adsorption on thin nanocrystalline diamond, Phys. Status Solidi A 208 (2011) 2093-2098.

[11] W.S. Yeap, Y.Y. Tan, K.P. Loh, Using detonation nanodiamond for the specific capture of glycoproteins, Anal. Chem. 80 (2008) 4659-4665.

[12] X. Wang, Y. Ishii, A.R. Ruslinda, M. Hasegawa, H. Kawarada, Effective surface functionalization of nanocrystalline diamond films by direct carboxylation for PGDF detection via aptasensor, ACS Appl. Mater. Interfaces 4 (2012) 3526-3534.

[13] B. van Grinsven, N. Vanden Bon, H. Strauven, L. Grieten, M. Murib, K.L. Jimenez Monroy, S.D. Janssens, K. Haenen, M.J. Schöning, V. Vermeeren, M. Ameloot, L. Michiels, R. Thoelen, W. De Ceuninck, P. Wagner, Heat-transfer resistance at solid-liquid interfaces: a tool for the detection of single-nucleotide polymorphisms in DNA, ACS Nano 6 (2012) 2712-2721.

[14] E.R. Martin, E.H. Lai, J.R. Gilbert, A.R. Rogala, A.J. Afshari, J.R., K.L. Finch, J.F. Stevens, K.J. Livak, B.D. Slotterbeck, S.H. Slifer, L.L. Warren, P.M. Conneally, D.E. Schmechel, I. Purvis, M.A. Pericak-Vance, A.D. Roses, J.M. Vance, SNPing away at complex diseases: analysis of single-nucleotide polymorphisms around APOE in Alzheimer disease, Am. J. Hum. Genet. 67 (2000) 383-394.

[15] P. Guldberg, F. Rey, J. Zschocke, V. Romano, B. Francois, L. Michiels, K. Ullrich, G.F. Hoffmann, P. Burgard, H. Schmidt, C. Meli, E. Riva, I. Dianzani, A. Ponzone, J. Rey, F. Güttler, A European multicenter study of phenylalanine hydroxylase deficiency: classification of 105 mutations and a general system for genotype-based prediction of metabolic phenotype, Am. J. Hum. Genet. 63 (1998) 71-79.

[16] A.M. Dunning, C.S. Healey, P.D.P. Pharoah, M.D. Teare, B.A.J. Ponder, D.F. Easton, A systematic review of genetic polymorphisms and breast cancer risk, Cancer Epidemiol. Biomark. Prev. 8 (1999) 843-854.

[17] P. Harald, K. Berggrav, P. Thomas, Y. Pfeiffer, W. Witte, K. Templeton, T.T. Bachman, Direct detection and genotyping of Klebsiella pneumoniae carbapenemases from urine by use of a new DNA microarray test, J. Clin. Microbiol. 50 (2012) 3990-3997.

[18] H.C. den Bakker, A.I. Moreno Switt, C.A. Cummings, K. Hoelzer, L. Degoricija, L.D. Rodriguez-Rivera, E.M. Wright, R. Fang, M. Davis, T. Root, D. Schoonmaker-Bopp, K.A. Musser, E. Villamil, H. Waechter, L. Kornstein, M.R. Furtado, M. Wiedmann, A whole-genome single nucleotide polymorphism-based approach to trace and identify outbreaks linked to a common Salmonella enterica subsp. enterica serovar montevideo pulsed-field gel electrophoresis type, Appl. Environ. Microbiol. 77 (2011) 8648-8655.

[19] T.F. Ducey, B. Page, T. Usgaard, M.K. Borucki, K. Pupedis, T.J. Ward, A singlenucleotide-polymorphism-based multilocus genotyping assay for subtyping lineage I isolates of Listeria monocytogenes, Appl. Environ. Microbiol. 73 (2007) 133-147.

[20] B. Lievens, L. Claes, A. Vanachter, B. Cammue, B. Thomma, Detecting single nucleotide polymorphisms using DNA arrays for plant pathogen diagnosis, FEMS Microbiol. Lett. 255 (2006) 129-139.

[21] A. Justé, B. Lievens, I. Frans, M. Klingeberg, C.W. Michiels, K.A. Willems, Development of a DNA array for the simultaneous detection and identification of sugar thick juice bacterial contaminants, Food Anal. Methods 4 (2011) 173-185.

[22] S.D. Janssens, S. Drijkoningen, M. Saitner, H.-G. Boyen, P. Wagner, K. Larsson, K. Haenen, Phase separation of ethanol-water solutions at a hydrogen terminated nanocrystalline diamond surface, J. Chem. Phys. 137 (2012) 044702.

[23] S. Wenmackers, S.D. Pop, K. Roodenko, V. Vermeeren, O.A. Williams, M. Daenen, O. Douhéret, J. D'Haen, A. Hardy, M.K. Van Bael, K. Hinrichs, C. Cobet, M. vandeVen, M. Ameloot, K. Haenen, L. Michiels, N. Esser, P. Wagner, Structural and optical properties of DNA layers covalently attached to diamond surfaces, Langmuir 24 (2008) 7269-7277.

[24] A.M. Christensen, D.A. Chang-Yen, B.K. Gale, Characterization of interconnects used in PDMS microfluidic systems, J. Micromech. Microeng. 15 (2005) 928-934.

[25] X.F. Guo, A.A. Gorodetsky, J. Hone, J.K. Barton, C. Nuckolls, Conductivity of a single DNA duplex bridging a carbon nanotube gap, Nat. Nanotechnol. 3 (2008) 163-167.

[26] M. Lenz, G. Striedl, U. Fröhler, SMD Packages., Thermal resistance, theory and practice. Released by Infineon Technologies AG, Munich, Germany, 2000.

[27] H. Urakawa, S. El Fantroussi, H. Smidt, J.C. Smoot, E.H. Tribou, J.J. Kelly, P.A. Noble, D.A. Stahl, Optimization of single-base-pair mismatch discrimination in oligonucleotide microarrays, Appl. Environ. Microbiol. 69 (2003) 2848-2856.

[28] B. Guan, K. Wang, B.-L. Zhou, W.-Z. Guo, T.-Z. Zhang, Establishment of a multi-color genomic in situ hybridization technique to simultaneously discriminate the three interspecific hybrid genomes in Gossypium, J. Integr. Plant Biol. 50 (2008) 345-351.

[29] N. Tibanyenda, S.H. Debruin, C.A.G. Haasnoot, G.A. Van Der Marel, J.H. Van Boom, C.W. Hilbers, The effect of single base-pair mismatches on the duplex stability of d(T-A-T-T-A-A-T-A-T-C-A-A-G-T-T-G)*d(C-A-A-C-T-G-A-T-A-T-T-A-A-T-A), Eur. J. Biochem. 139 (1984) 19-27. 